\title{
43316 - SELF-PERCEIVED IMPACT OF SLEEP DEPRIVATION IN ANESTHESIA RESIDENTS
}

\author{
Viren Naik, St. Michael's Hospital, University of Toronto, Toronto, ON, Canada; \\ Augustine Rhee, St Michael's Hospital, University of Toronto; \\ Sarah Woodrow, St Michael's Hospital, University of Toronto; \\ D Weiss, St Michael's Hospital, University of Toronto; \\ G Savoldelli, St Michael's Hospital, University of Toronto; \\ H Joo, St Michael's Hospital, University of Toronto;
}

INTRODUCTION: "On call" duties for anesthesiology residents are normally 24 hours. Such practices are believed to improve education by increasing clinical exposure and experience. However, there is evidence to suggest that acute and chronic sleep deprivation produces a decrease in neurobehavioral and psychomotor performance that may result in compromised patient safety.(1) We conducted this study to evaluate the self-perceived impact of sleep deprivation among anesthesia residents at a tertiary care university. These results were compared to existing data collected for non-anesthesia residents at the same institution during the same time frame.

METHODS: After institutional ethics approval, a survey was distributed to all anesthesia residents on anesthesia rotations. Sleepiness was quantified using the Epworth Sleepiness Scale (ESS). The ESS consists of 12 subjective scales, requiring individuals to rate their immediate likelihood of falling asleep in different common scenarios. Higher ESS scores reflect a greater degree of sleepiness. The perceived impact of sleep deprivation on performance was measured using the Sleep Deprivation Index (SDI). The SDI is comprised of 18 scales with higher scores reflecting greater concerns in perceived performance due to sleep loss. Comparisons were made between anesthesia, surgical, and non-surgical (internal medicine and psychiatry) groups. RESULTS: Thirty-one of $43(72 \%)$ anesthesia residents participated in the study. Anesthesia residents reported working fewer hours $(\mathrm{p}<0.01)$, but averaged less hours of sleep while on-call than surgical residents $(\mathrm{p}<0.05)$. Using the ESS and SDI, anesthesia residents reported that they were sleepier than non-surgical residents $(\mathrm{p}<0.01)$ even though reported hours worked per week, and hours of sleep on call were similar. 


\begin{tabular}{|c|c|c|c|}
\hline & $\begin{array}{l}\text { Anesthesin } \\
(n=31)\end{array}$ & $\begin{array}{l}\text { Surgery } \\
(\mathrm{n}=95)\end{array}$ & $\begin{array}{l}\text { Nor- } \\
\text { Surgery } \\
\text { in=194) }\end{array}$ \\
\hline Epworth Sleqiness Scale & $\begin{array}{c}1207 \\
( \pm 66)\end{array}$ & $\begin{array}{c}12.84 \\
( \pm 4.7)\end{array}$ & $\begin{array}{c}9.17 \\
( \pm 48)^{4}\end{array}$ \\
\hline Sleep Depri atian Irdex & $\begin{array}{c}458 \\
( \pm 6.4)\end{array}$ & $\begin{array}{c}452 \\
( \pm 8.7)\end{array}$ & $\begin{array}{c}515 \\
\vdots \pm 597\end{array}$ \\
\hline Houns of workper week & $\begin{array}{c}625 \\
( \pm 148)\end{array}$ & $\begin{array}{c}830 \\
( \pm 12.1\rangle^{*}\end{array}$ & $\begin{array}{c}625 \\
( \pm 16.1\rangle\end{array}$ \\
\hline Hours of sleep on-call & $\begin{array}{c}255 \\
( \pm 12)\end{array}$ & $\begin{array}{c}326 \\
( \pm 1.4)^{4 *}\end{array}$ & $\begin{array}{c}288 \\
( \pm 201)\end{array}$ \\
\hline $\begin{array}{l}\text { Mirimm amount of sleep in } \\
\text { hours to perform clinical } \\
\text { duties well }\end{array}$ & $65( \pm 16)$ & $\begin{array}{c}46 \\
( \pm 18)^{*}\end{array}$ & $\begin{array}{c}49 \\
( \pm 1.7)^{*}\end{array}$ \\
\hline
\end{tabular}

DISCUSSION: Our results demonstrate that anesthesia residents perceived their work week, sleep on call, sleepiness, and affect of sleep deprivation differently from other specialties. Interestingly, anesthesia residents reported that they were as sleepy, and as affected by sleep deprivation as surgical trainees, but had a similar work week to non-surgical trainees. The unique nature of anesthesia "on call" duties in terms of intensity, type of work, and timing of work may account for these findings. Further studies are warranted to objectively quantify these self perceptions, for potential future resident work hour reforms.

REFERENCES: (1) JAMA 2002; 288(9): 1116-24. 